\title{
Lumbar disc herniation in a child with cystic fibrosis. Case report
}

\author{
George A. Alexiou $M D, P h D^{1}$, Kalliopi Stefanaki $M D, P h D^{2}$, George Sfakianos $M D, P h D^{1}$, \\ Neofytos Prodromou MD, $P h D^{1}$
}

\begin{abstract}
We report a case of child with cystic fibrosis and lumbar disc herniation. An 8-year-old boy presented with low back pain that exacerbated on coughing, sitting, walking, or bending and diminished when lying down. The straight leg raising test was positive when the right leg was lifted at 60 degrees. Crossed leg raising test was negative. Lumbar MRI revealed a L5-S1central disc protrusion. Conservative treatment was not effective and the patient underwent surgery. Postoperatively the patient experienced regression of the pain. To the best of our knowledge this is the first reported case of lumbar disc herniation in a child with cystic fibrosis. Although this case might be coincidental, thorough investigation of back pain, which is frequent in patients with cystic fibrosis, should be performed.
\end{abstract}

Key words: lumbar disc herniation; children; cystic fibrosis.

http:/ /dx.doi.org/10.5546/aap.2014.eng.e43

\section{INTRODUCTION}

Lumbar disc herniation (LDH) is a common condition in adults, nevertheless in children is extremely rare. ${ }^{1}$ The causes of $\mathrm{LDH}$ in children are still unclear, whereas a delay in diagnosis has been reported due to LDH rarity. ${ }^{1}$ Cystic fibrosis is an autosomal recessive disorder with a rate of 1 case per 2,500 births and the lungs are one of the primary organs affected. Back pain is a common complaint in patients with cystic fibrosis. ${ }^{2}$ Recently, Denne et al. reported three adult patients with cystic fibrosis who experienced LDH in the course of their disease. ${ }^{2}$ We report the first case of lumbar disc herniation treated surgically in a child with cystic fibrosis.

1. Department of Neurosurgery.

2. Department of Pathology.

Children's Hospital "Agia Sofia", Athens, Greece.

E-mail Address:

George Alexiou, MD: alexiougrg@yahoo.gr

Conflict of interest: Ninguno que declarar.

Received: 22-7-2013

Accepted: 9-8-2013

\section{CASE REPORT}

An 8-year-old boy, diagnosed with cystic fibrosis at three years of age (genetic analysis identified the F508 mutation) presented with low back pain, buttock pain and abnormal gait that gradually worsen over the last 3 months. His body weight was within the 10-25 percentile interval. The child had persistent cough and had been hospitalized two month ago due to respiratory infection. The child reported that the pain was aggravated by sitting, walking, or bending and diminished by lying down with the knees flexed. Furthermore, the pain tended to exacerbate on coughing. The patient reported no disturbances in bowel or bladder function and had no fever. Physical examination revealed no decrease in strength or sensibility. The straight leg raising test was positive when the right leg was lifted at 60 degrees. Crossed leg raising test was negative. The right side Achilles tendon reflex was diminished. Differential diagnosis included trauma, muscle strain, idiopathic causes, urinary tract infection, viral syndrome, spinal abscess and lumbar disc herniation. Lumbar MRI revealed a L5-S1 central disc protrusion with thecal sac compression (Figure 1 and 2). Conservative treatment failed to relieve the symptoms. The patient underwent surgery; a L5 laminectomy and L5-S1 discectomy was performed to decompress the spinal canal. Histological examination showed fragments of degenerative cartilaginous and connective tissue, with focal myxoid and microcystic degeneration. There were also clusters of chondrocytes with degenerative appearance and focal neovascularization. Alcian blue staining was positive in areas of myxoid pattern. Postoperatively the patient experienced regression of the pain. On follow-up examination 6 months later no signs of recurrence were noted.

\section{DISCUSSION}

Back pain is fairly prevalent in healthy children and adolescents. ${ }^{3}$ Szpalski, et al. prospectively studied 287 children, aged between 9-12 years, over a 2 year period and found that $17.8 \%$ reported to suffer at least one episode of 
FIGURE 1. Sagital T2-weighted MRI image of the lumbar spine showing a disc herniation at L5/S1 (arrow)

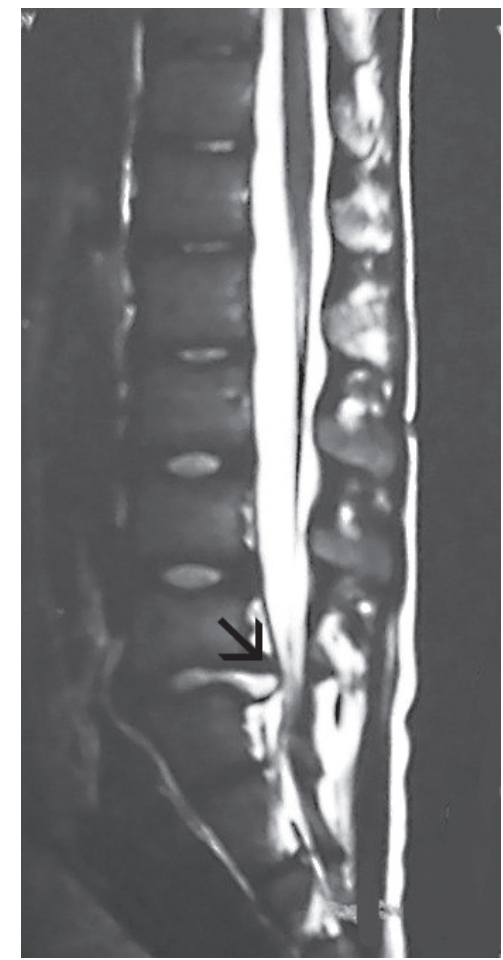

low back pain. ${ }^{3}$ Differential diagnosis include trauma, muscle strain, sickle cell crisis, idiopathic cause, urinary tract infection, viral syndrome and serious spinal disease such as tumor and infection. ${ }^{3,4}$ Detailed patient's history and physical examination may narrow the differential. Lumbar disc herniation is exceedingly rare in children. In the population younger than 25 years of age, the number of LDH requiring surgical treatment is 5.5 per 100,000 person years. ${ }^{5}$ The cause of $\mathrm{LDH}$ in this age group more frequent is trauma, followed by congenital malformation, familial predisposition and vertebral slipping epiphysis. ${ }^{1}$ Patient's usually present with back pain, radiculopathy and motor or sensory loss. Examination of the deep tendon reflexes may reveal diminished reflexes depending on the nerve root that is compressed. The straight legraising test is one of the most important tests in the diagnosis of LDH. Electrodiagnostic studies are also helpful in the diagnosis of lumbar radiculopathy because are very specific and constitute a good complement to lumbar MRI, ${ }^{6}$ which is the examination of choice to diagnose a herniated lumbar disc. Conservative treatment
FIGURE 2. Axial T2-weighted MRI image revealing disc herniation with marked impingement on the neural canal (arrow)

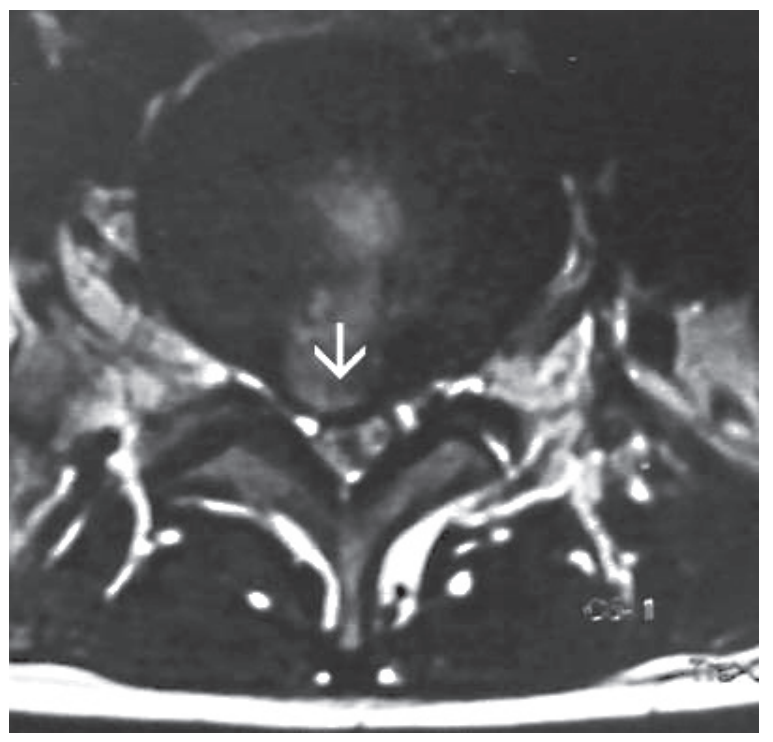

may include simple bed rest and administration of nonsteroidal anti-inflammatory drugs. The indications for surgery are failure of conservative treatment for 3 months, intractable pain and/or progressive neurological impairment. ${ }^{1}$ Depending on the size and location of the disc prolapse, open discectomy or microdiscectomy can be performed. ${ }^{7}$ Regarding outcome, in a prospective study comparing children with adults, the pediatric LDH group was postoperatively better than the adult group both clinically and radiologically. ${ }^{8}$

Cystic fibrosis is one of the most commonly inherited autosomal recessive disorders among caucasians. With the improved survival rates, chronic pain becomes a common problem in patients with this disorder. ${ }^{9}$ Back pain is a common complaint in patients with cystic fibrosis. ${ }^{9,10}$ In adults back pain is usually attributed to problems with bone mineralization, chronic cough and steroid use. ${ }^{10} \mathrm{LDH}$ in cystic fibrosis has been reported previous in only one study that included 3 adult patients. ${ }^{2}$ Regarding the effect of back pain in cystic fibrosis, Denne et al. reported a case of a patient with LDH who died because of the deteriorated pulmonary situation, which was influenced by LDH, since pulmonary drainage techniques could not be properly performed as a result of pain. ${ }^{2}$ In children with cystic fibrosis, pain was reported in $59 \%$ of patient and back 
pain was the chief complaint in 16 out of $73(22 \%)$ children. ${ }^{11}$ To the best of our knowledge this is the first reported case of LDH in a child with cystic fibrosis. Although this case might be coincidental, chronic cough has been reported as a risk factor for LDH. ${ }^{12}$ Furthermore, the intervertebral disc is composed of the highly hydrated nucleus pulposus, the surrounding annulus fibrosus, and the cartilaginous endplate. ${ }^{13}$ Cells in the nucleous pulposus are round and express a proteoglycan rich matrix, whereas the more elongated annulus fibrosus cells are embedded in a collagen fibre matrix and the cartilaginous endplate is a layer of cartilage. ${ }^{13}$ In cystic fibrosis, extracellular matrix architecture may be abnormal and sulfation of glycoconjugates by some organs and sulfate utilization in others may be affected. ${ }^{14}$ Apart from that, patients with cystic fibrosis have bone demineralization and imbalance between bone formation and degradation. ${ }^{15}$ Thus, since a healthy intervertebral disc balance the slow matrix turnover of synthesis and degradation, in cystic fibrosis an imbalance might also exist.

In conclusion, back pain should be thorough investigated in the pediatric age group and lumbar disc herniation although rare should be excluded. In cystic fibrosis back pain is a common complaint, nevertheless thorough investigation is needed.

\section{REFERENCES}

1. Haidar R, Ghanem I, Saad S, Uthman I. Lumbar disc herniation in young children. Acta Paediatr 2010;99:19-23.

2. Denne C, Vogl-Voswinckel AE, Wurmser H, Steinborn M, et al. Lumbar disc herniation in three patients with cystic fibrosis: a case series. J Med Case Rep 2011;5:440.

3. Szpalski M, Gunzburg R, Balague F, Nordin M, Melot C. A 2-year prospective longitudinal study on low back pain in primary school children. Eur Spine J 2002;11:459-64.

4. Selbst SM, Lavelle JM, Soyupak SK, Markowitz RI. Back pain in children who present to the emergency department. Clin Pediatr (Phila) 1999;38:401-6.

5. Bruske-Hohlfeld I, Merritt JL, Onofrio BM, Stonnington $\mathrm{HH}$, et al. Incidence of lumbar disc surgery. A populationbased study in Olmsted County, Minnesota, 1950-1979. Spine (Phila Pa 1976) 1990;15:31-5.

6. Barr K. Electrodiagnosis of lumbar radiculopathy. Phys Med Rehabil Clin N Am 2013;24:79-91.

7. Thomas JG, Hwang SW, Whitehead WE, Curry DJ, et al. Minimally invasive lumbar microdiscectomy in pediatric patients: a series of 6 patients. J Neurosurg Pediatr 2011;7:616-9.

8. Çelik S, Göksu K, Çelik SE, Emir CB. Benign neurological recovery with low recurrence and low peridural fibrosis rate in pediatric disc herniations after lumbar microdiscectomy. Pediatr Neurosurg 2011;47:417-22.

9. Ravilly S, Robinson W, Suresh S, Wohl ME, et al. Chronic pain in cystic fibrosis. Pediatrics 1996;98:741-7.

10. Tattersall R, Walshaw MJ. Posture and cystic fibrosis. J $R$ Soc Med 2003;43:18-22.

10. Sermet-Gaudelus I, De Villartay P, de Dreuzy P, Clairicia $\mathrm{M}$, et al. Pain in children and adults with cystic fibrosis: a comparative study. J Pain Symptom Manage 2009;38:281-90.

11. Heliövaara M, Knekt P, Aromaa A. Incidence and risk factors of herniated lumbar intervertebral disc or sciatica leading to hospitalization. J Chronic Dis 1987;40:251-8.

12. Pattappa G, Li Z, Peroglio M, Wismer N, et al. Diversity of intervertebral disc cells: phenotype and function. J Anat 2012;221:480-96.

13. Hill WG, Harper GS, Rozaklis T, Boucher RC, Hopwood JJ. Organ-specific over-sulfation of glycosaminoglycans and altered extracellular matrix in a mouse model of cystic fibrosis. Biochem Mol Med 1997;62:113-22.

14. Baroncelli GI, De Luca F, Magazzú G, Arrigo T, et al. Bone demineralization in cystic fibrosis: evidence of imbalance between bone formation and degradation. Pediatr Res 1997;41:397-403. 